\title{
Recurrent Cutaneous Rosai-Dorfman Disease
}

\author{
Oren Michaeli ${ }^{1}$, Mohammed Elassa ${ }^{2}$, Richard Williams ${ }^{3}$, Gerard Baltazar ${ }^{4}$ \\ 1. General Surgery, NYU Winthrop Hospital, Mineola, USA 2. General Surgery, Rowan University School of Osteopathic \\ Medicine, Stratford, USA 3. Surgery, Carepoint Health Bayonne Medical Center, Bayonne, USA 4. Surgery, NYU \\ Winthrop Hospital, Mineola, USA
}

Corresponding author: Oren Michaeli, oren.michaeli@nyulangone.org

\section{Abstract}

Rosai-Dorfman disease (RDD) is a rare proliferative histiocytic disorder, most commonly presenting with cervical lymphadenopathy. When extranodal, a rare manifestation of the disease is the presence of cutaneous lesions. Surgical excision has shown promising results in patients with cutaneous RDD; however, no optimal management has been elucidated. We present a 60-year-old female with recurrence of left thigh cutaneous lesions consistent with extranodal RDD whose optimal management required combined used of excision and chemotherapy.

Categories: Pathology, General Surgery, Hematology

Keywords: rosai dorfman, extranodal, histiocytosis

\section{Introduction}

Rosai-Dorfman disease (RDD) is a rare proliferative histiocytic disorder first reported in 1969 by Juan Rosai and Ronald Dorfman. Most commonly, the clinical presentation of RDD is massive, painless cervical lymphadenopathy with varying symptoms dependent upon involved organ systems [1]. RDD has been reported in patients of a wide age-range with predominance among younger adults. Cutaneous RDD lesions are exceedingly rare, and recurrence of a cutaneous lesion after excision has only been reported once [2]. We present the second case of cutaneous recurrence of RDD with metastatic behavior that required optimal treatment with excision and chemotherapy.

\section{Case Presentation}

At initial presentation, the patient was a 58-year-old African American female who presented to a general surgical clinic with a left lateral proximal thigh cutaneous nodules for one-year duration. She complained of $15+$ mildly tender nodules that were gradually increasing in size and unrelated to trauma or infection. Previous excisional biopsy at an outside institution had revealed RDD.

Received 11/26/2019

Review began 11/26/2019 Review ended 12/01/2019 Published 12/04/2019

(c) Copyright 2019 Michaeli et al. This is an open access article distributed under the terms of the Creative Commons Attribution License CC-BY 3.0., which permits unrestricted use, distribution, and reproduction in any medium, provided the original author and source are credited.
Our general surgery team carried out a wide local full-thickness excision of the left thigh tumor-involved skin and subcutaneous tissue with a split-thickness skin graft (STSG) performed in February 2017, encompassing all nodules and with grossly clear margins.

Histopathology showed predominant histiocytes and macrophages with abundant eosinophilic cytoplasm that ranged from round- to spindle-shaped. Emperiolysis was noted in histiocytes and macrophages throughout the samples. These morphological features with concomitant positive reactivity for S100 (family of soluble in $100 \%$ saturated solution of ammonium sulfate) and cluster of differentiation (CD)68 supported the diagnosis of RDD (Figure 1). 


\section{Cureus}
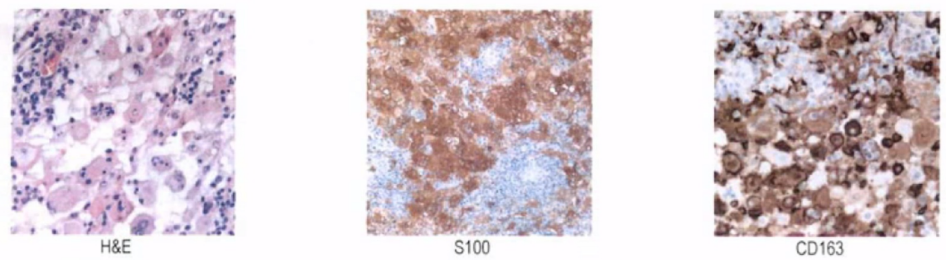

$\begin{array}{lll}\text { Marker } & \text { Result } & \text { Description } \\ \text { S100 } & \text { Positive } & \text { S100 Protein, Nerve Sheath Tumor, Melanomas, Chondrocytes } \\ \text { CD68 } & \text { Positive } & \text { Macrophages and Myeloid Cells (KP1) } \\ \text { CD1A (010) } & \text { Negative } & \text { Cortical Thymocytes, Langerhans Cells (O10) } \\ \text { FACTOR 13A } & \text { Negative } & \text { Fibrohistiocytic Tumors, Dendritic Interstitial Cells } \\ \text { PANMEL } & \text { Negative } & \text { Melanoma and Melanocytic Lesions } \\ \text { AE1-AE3 } & \text { Negative } & \text { Keratins: 40, 48, 50, 52, 54, 56.5, 58, 59, 64, 65, 67 } \\ & & \\ \text { Marker } & \text { Result } & \text { Description } \\ \text { EMA } & \text { Plasma Cells Positive } & \text { Epithelial Membrane Antigen (E29) } \\ \text { CD20 } & \text { B-cells Positive } & \text { Pan B Cell Antigen (L26) } \\ \text { CD3 } & \text { T-cells Positive } & \text { Pan T Cell, Epsilon Sub-Unit of the CD3 T Cell Receptor } \\ \text { CD30 } & \text { Negative } & \text { Complex } \\ \text { CD138 } & \text { Plasma Cells Positive } & \text { Activated T, B, Reed-Stemberg Cells, ALCL (Ki-1, BerH2) } \\ \text { MUM1 } & \text { Plasma Cells Positive } & \text { Plasma Cells and Subset of Epithelial Cells } \\ \text { ALK-1 } & \text { Negative } & \text { Plasma Cells Post Germinal Center B-Cells, Activated T-Cells } \\ \text { IgG4 } & \text { Plasma Cells Positive } & \text { Anaplastic Lymphoma Kinase, Anaplastic Large Cell Lymphoma } \\ \text { CD4 (4B12) } & \text { Few Cells Positive } & \text { Autoimmune diseases related to IgG4 } \\ \text { CD21 } & \text { Negative } & \text { Helper/lnducer T Cells, Thymocyte and Monocyte Subsets } \\ \text { CD35 } & \text { Negative } & \text { C3d and EBV Receptor, Mature B Cells, Follic. Dendritic Cells } \\ \text { CD163 } & \text { Positive } & \text { Dendritic Cells, C3b Receptor (Ber-MAC-DRC) } \\ \text { SMA } & \text { Negative } & \text { Marker for Monocyte/Macrophage Lineage Cells } \\ \text { DESMIN } & \text { Negative } & \text { Smooth Muscle Actin, Myofibroblasts, Myoepithelial Cells (1A4) } \\ \text { Marker } & \text { Result } & \text { Muscle, Desmoplastic Small Round Cell Tumor } \\ \text { KAPPA ISH } & \text { Plasma Cells Positive } & \text { Description } \\ \text { LAMBDA ISH } & \text { Plasma Cells Positive } & \text { Kappa Immunoglobulin Light Chain, B Cells and Plasma Cells - } \\ & & \text { RNA } \\ \text { Lambda Immunoglobulin Light Chain, B Cells and Plasma Cells - }\end{array}$

FIGURE 1: Slides provided show H\&E, S100 and CD163 staining; of note, excisional samples were positive for S100/CD68, markers classically associated with RDD

H\&E: Hematoxylin and eosin stain; S100: Family of soluble in $100 \%$ saturated solution of ammonium sulfate; CD - Cluster of differentiation; MUM - Multiple myeloma oncogene; RDD: Rosai-Dorfman disease.

In November 2017, the patient returned to the general surgery clinic with a complaint of a nodule on the left lateral proximal thigh, proximal to the split-thickness skin graft (STSG) in virgin tissue. Physical examination revealed non-tender, rubbery, grape-sized nodule that was freely mobile in the lateral plane and fixed to underlying tissues in the vertical plane. Wide local excision revealed diseased tissue extending and invading into the left iliotibial band. During the operation, additional lesions were palpated within the subcutaneous tissues, and dissection was continued until grossly negative margins were obtained. What was believed to be a minor lesion resulted in the excision of most of the iliotibial band.

Specimens and slides were submitted to a specialized cutaneous pathologist. The pathology demonstrated atypical mononuclear and multinuclear cell proliferation with multifocal emperipolesis most consistent with RDD with extensive areas of expansive aggregates of histiocytes positive for S100 and CD68 consistent with RDD with sarcomatous features.

On September 2018 as a component of follow up, a positron emission tomography/computed tomography (PET/CT) was conducted which was significant for a third recurrence this time with multiple subcutaneous soft tissue nodules noted in the lower back at the level of L4 and in bilateral thighs, demonstrating increased fluorodeoxyglucose (FDG) uptake suggestive of cutaneous extranodal RDD (Figure 2). 


\section{Cureus}
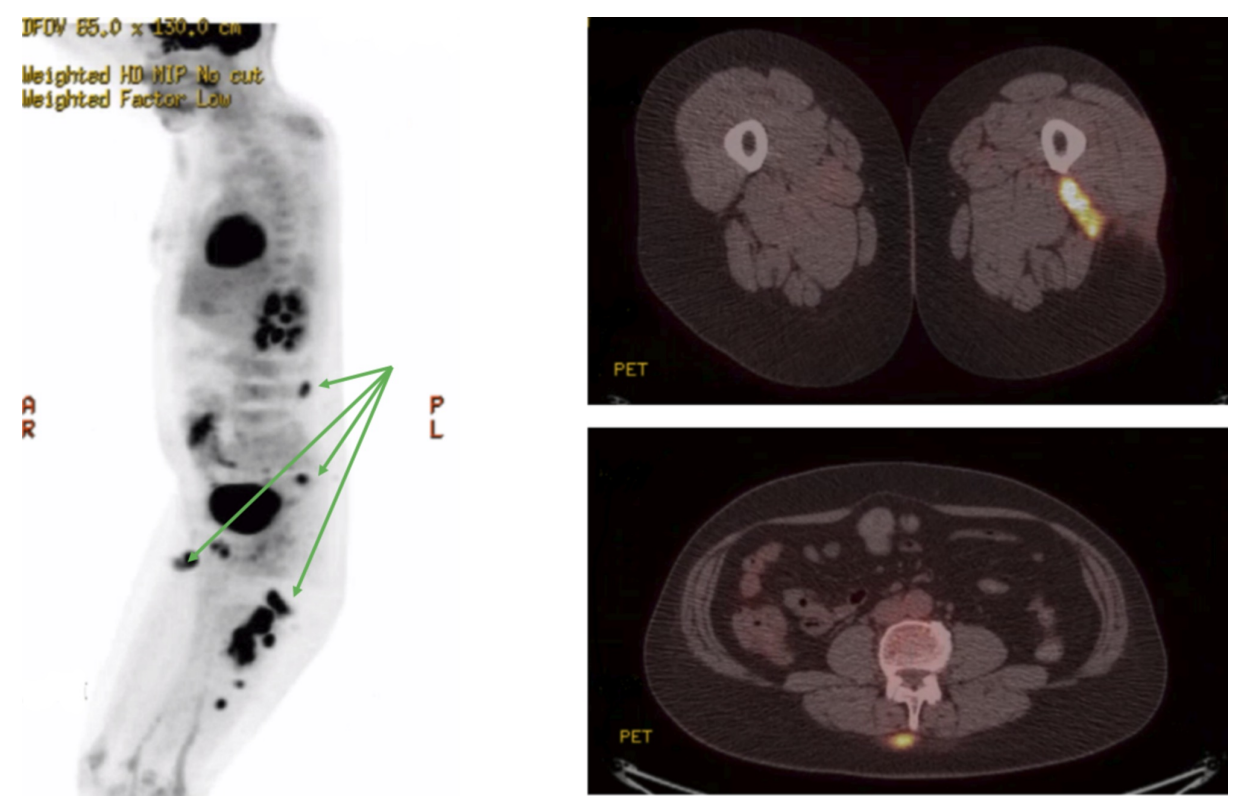

FIGURE 2: Imaging depicts multiple subcutaneous soft tissue nodules noted in the lower back at the level of L4 and in the bilateral thighs demonstrating increased fluorodeoxyglucose (FDG) uptake suggestive of cutaneous extranodal Rosai-Dorfman disease

After the failure of multiple excisions, the multidisciplinary team overseeing her care decided to explore medical options, and the patient received intravenous cladribine (Mavenclad) daily for one week. At the first post-chemotherapy follow up with the general surgeon two months later, the palpable masses near the patient's spine and in bilateral thighs had decreased in size to a negligible amount. Thereafter, she remained asymptomatic.

\section{Discussion}

RDD is identified histologically as histiocytes containing a vesicular nucleus and abundant cytoplasm with accompanying emperipolesis (i.e. lymphophagocytosis) of lymphocytes or plasma cells. The histiocytes are predominantly S100-positive and also tend to express positivity for macrophage lineage marker CD68 while the plasma cells are typically polyclonal [3].

Although most-commonly confined within the cervical lymph nodes, one study showed up to $23 \%-40 \%$ of patients with RDD may present with extranodal proliferation, with the most common sites of being the skin, bones, and upper respiratory tract [4]. Patients with extranodal involvement commonly present with concurrent nodal involvement as well. Purely extranodal disease is extremely rare; it has been reported to be as low as only $3 \%$ of patients of RDD [5].

The cutaneous form of the disease generally presents as deep red papules, plaques or nodules that may change in appearance over time. The cutaneous form of the disease has been reported to have a marked female predominance and a wide age distribution and without a predilection for a specific site of the body [6]. Although categorized as cutaneous, the skin lesions can infiltrate into underlying structures creating not only cosmetic complaints but also functional deficits.

For the purposes of evaluation and staging, a widely utilized method is 18F-FDG PET/CT. Reports have shown that RDD lesions have considerable avidity for FDG as a result of their intense glucose dependence secondary to the energy requirements of proliferating histiocytes/lymphocytic inflammatory cells [5]. Imaging results are not utilized for diagnostic purposes, instead, a biopsy is required for confirmation of RDD.

Our patient benefited from follow-up PET/CT which revealed the metastatic-like behavior, prompting successful chemotherapy treatment.

Optimal treatment guidelines for RDD have not been established. Treatment plans are generally dependent on the extent and severity of the individual patient's disease. Treatment guidelines have included operation, chemotherapy, steroids or other immunomodulatory medications. Reports have indicated a promising potential for the use of surgical intervention in the management of the cutaneous form of the RDD with no 
Our patient's case was refractory to multiple excisions due to the metastatic-like behavior of this subset of Rosai-Dorfman lesions. Thus, chemotherapy with cladribine was necessary to effect a cure.

To our knowledge, we present the second case of recurrent cutaneous RDD and the first such disease with metastatic- and sacroma-like behavior. For similar cases, we recommend the early combined use of wide local excision and intravenous cladribine chemotherapy.

\section{Conclusions}

Cutaneous RDD is an extremely rare and complex benign soft tissue disorder. We present the second case of recurrent cutaneous RDD and one with rare metastatic- and sarcoma-like behavior. Chemotherapy with intravenous cladribine in combination with wide local excisions led to regression of disease, and this combination may be the optimal treatment for such aggressive cutaneous RDD.

\section{Additional Information \\ Disclosures}

Human subjects: Consent was obtained by all participants in this study. Conflicts of interest: In compliance with the ICMJE uniform disclosure form, all authors declare the following: Payment/services info: All authors have declared that no financial support was received from any organization for the submitted work. Financial relationships: All authors have declared that they have no financial relationships at present or within the previous three years with any organizations that might have an interest in the submitted work. Other relationships: All authors have declared that there are no other relationships or activities that could appear to have influenced the submitted work.

\section{References}

1. Histiocyte society: Rosai-Dorfman disease. (2011). Accessed: October 10, 2019: https://www.histio.org/document.doc?id=810.

2. Komaragiri M, Sparber L, Zabala M, Dardik M, Chamberlain S: Extranodal Rosai-Dorfman disease: a rare soft tissue neoplasm masquerading as a sarcoma. World J Surg Oncol. 2013, 11:63. DOI: 10.1186/1477-7819-1163

3. Warpe BM, More SV: Rosai- Dorfman disease: a rare clinico-pathological presentation. Australas Med J. 2014, 7:68-72. 10.4066/AMJ.2014.1931

4. Orr AR, Lefler D, Deshpande C, Kumar P: Extranodal Rosai-Dorfman disease presenting as a mediastinal mass with pulmonary artery invasion. Case Rep Hematol. 2018, 1-5. 10.1155/2018/3915319

5. Shaikh F, Awan O, Mohiuddin S, Farooqui S, Khan S, McCartney W: 18F-FDG PET/CT imaging of extranodal Rosai-Dorfman disease with hepatopancreatic involvement - a pictorial and literature review. Cureus. 2015, 7:e392. 10.7759/cureus.392

6. Brenn T, Calonje E, Granter S, Leonard N, Grayson W, Fletcher C, Phillip P: Cutaneous Rosai-Dorfman disease is a distinct clinical entity. Am J Dermatopathol. 2002, 24:385-391. 10.1097/00000372-20021000000001

7. Cheng SP, Jeng KS, Liu CL: Subcutaneous Rosai-Dorfman disease: is surgical excision justified? J Eur Acad Dermatol Venereol. 2005, 19:747-750. 10.1111/j.1468-3083.2005.01297.x

8. Xu Y, Han B, Yang J, Ma J, Chen J, Wang Z: Soft tissue Rosai-Dorfman disease in child: a case report and literature review. Medicine (Baltimore). 2016, $95: e 4021.10 .1097 / M D .0000000000004021$ 